\title{
Thermodynamic Analysis of Moisture Adsorption of Taraxacum Officinale’ Powder
}

\author{
Haytem Moussaoui*, Zakaria Tagnamas, Younes Bahammou, Mounir Kouhila, Ali Idlimam, \\ Abdelkader Lamharrar \\ Team of Solar Energy and Aromatic and Medicinal Plants, ENS Marrakesh- Laboratory of Processes for Energy \\ \& Environment ProcEDE, Cadi Ayyad University, Morocco \\ E-mail: Haytem.moussaoui@gmail.com
}

Received: 15 October 2020; Accepted: 6 November 2020; Available online: 20 November 2020

\begin{abstract}
This work aims to model the adsorption isotherms and study the essential thermodynamic properties of Taraxacum Officinale' powder during the moisture adsorption phenomenon at three temperatures 30,40 , and $50^{\circ} \mathrm{C}$. The results have been determined by the application of the thermodynamics physical principles to the equilibrium data, which are experimentally measured. The estimated values of the isokinetic and harmonic temperatures and the Gibbs free energy change revealed that the sorption process is non-spontaneous and enthalpy driven.
\end{abstract}

Keywords: Taraxacum Officinale; Moisture adsorption; Enthalpy; Entropy; Gibbs free energy.

\section{Introduction}

The Taraxacum Officinale powder is a therapeutic treatment whose benefits have been discovered since ancient times. The benefits of this powder were proven only in the sixteenth century [1]. Taraxacum Officinale has many properties that can act on the liver. They are effective for liver failure and seizures. Taraxacum Officinale powder also regulates intestinal functions. It can be considered as a natural diuretic and depurative. Moreover, its bitter principles stimulate digestive secretions. Also, it is useful against certain skin diseases [2-4].

The determination of the sorption isotherms is an indispensable step and a privileged way to know the distribution and the intensity of the water molecules bonds in the agro-alimentary products. These isotherms make it possible to determine the final water content to be reached in order to optimize the storage and drying conditions of this product and give valuable information about the hygroscopic equilibrium of the product to be dried and stored [5-7].

Knowledge of the thermophysical properties of the powder is a crucial step for the adequate use of the latter. It can also be deemed as a database for the design of industrial dryers as well as the optimization and simulation of drying processes. The essential thermodynamic properties of food products such as heat of sorption, enthalpy, entropy and free energy are necessary for certain thermal processes such as drying [8-10]. The isosteric of desorption heat is the additional heat to the latent heat to evaporate pure water molecules in the hygroscopic range. Knowledge of this parameter is important when designing industrial dryers for product preservation reasons [11].

Differential entropy is calculated from the Gibbs-Helmholtz equation. The knowledge of the change in isosteric heat and in differential entropy of sorption is necessary to characterize the association of molecules in the hygroscopic domain. Enthalpy-entropy compensation theory has been widely studied for different physical and chemical processes $[12,13]$. In the literature, information about the determination of desorption isotherms and the thermodynamic properties of the Taraxacum Officinale powder is lacking. Indeed, the objective of this work is to determine the desorption isotherms of the Taraxacum Officinale's leaves powder at three temperatures 30,40, and $50^{\circ} \mathrm{C}$, and to analyze the evolution of the isosteric heat of the differential entropy as a function of the equilibrium water content, and finally to verify the existence of enthalpy-entropy compensation theory during the Taraxacum Officinale powder desorption process.

\section{Material and methods}

\subsection{Plant material and preparation}

The Taraxacum Officinale's powder (figure 1) used in the study was collected in May 2019 in the "OULA SAID” area, Settat, Morocco at harvest stage maturity. This medicinal plant was obtained by the assistance of Mr. Mohammed Benouara, a phytotherapist in Settat. 

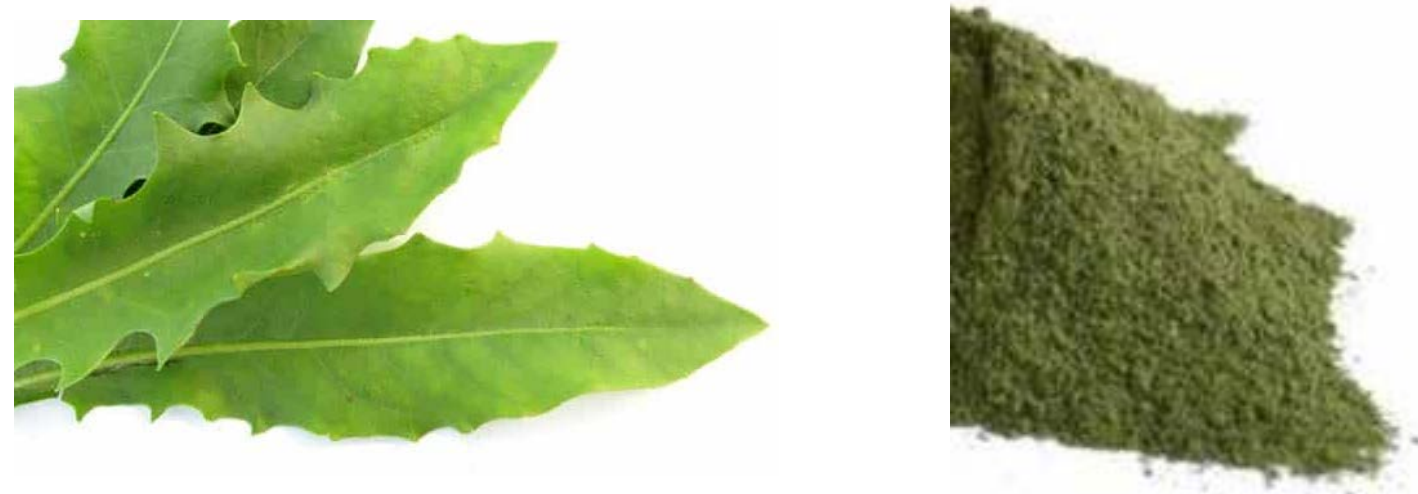

FIGURE 1. Taraxacum Officinale leaves and its powder

\subsection{Experimental procedure}

We opted for the static gravimetric method, and we used solutions of saturated salts: $\mathrm{KOH}$, (MgCl2, 6H2O), $\mathrm{K} 2 \mathrm{CO} 3, \mathrm{NaNO} 3, \mathrm{KCl}$ and $(\mathrm{BaCl} 2,2 \mathrm{H} 2 \mathrm{O})$. These solutions are prepared in hermetic jars and are kept in a controlled temperature oven. The sample is suspended in the jar, above the salts, and thus remains in an environment stabilized in temperature and humidity. The experiment is carried out for three temperatures 30, 40 and $50{ }^{\circ} \mathrm{C}$ (figure 2).

The mass of the product used for desorption is $0.500 \pm 0.001 \mathrm{~g}$. The monitoring of mass losses for desorption and mass gain for adsorption is ensured by a precision balance of $\pm 0.001 \mathrm{~g}$. The hygroscopic equilibrium is obtained when the exchange between the product and the ambient air is finished. As soon as the wet masses are determined, the samples are introduced into an oven at $105^{\circ} \mathrm{C}$. for 24 hours in order to determine their dry masses. The product undergoes a pre-drying stage before being submitted to the adsorption study phase. The pre-drying step is carried out in an oven heated to a temperature of $50^{\circ} \mathrm{C}$ until the maximum dehydration of the product [1416].

$\mathrm{EMC}=\mathrm{X}_{\mathrm{eq}}=\frac{\mathrm{M}_{\mathrm{h}}-\mathrm{M}_{\mathrm{S}}}{\mathrm{M}_{\mathrm{S}}}$

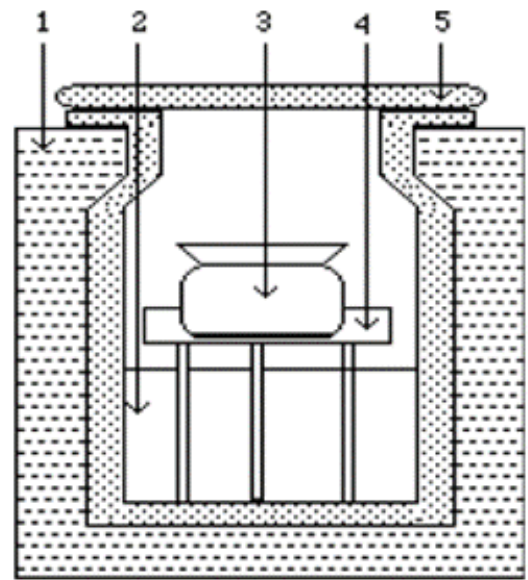

(1) Watertight glass jar, (2) Saturated salt solution, (3) Flask containing the product, (4)

Tripod, (5) Jar cover.

FIGURE 2. Experimental apparatus for the sorption isotherms measurement

\subsection{Mathematical modeling of sorption isotherms}

Several authors have proposed mathematical models in the empirical form to describe the graphical relationship between the equilibrium water content, the ambient relative humidity, and the temperature. In this work, we chose the Guggenheim Anderson-Boer (GAB) model. The expression of the GAB model is presented in the table 1. 
TABLE 1. Guggenheim Anderson-Boer (GAB) model

\begin{tabular}{cccc}
\hline Authors & Model & Parameters & Reference \\
\hline $\begin{array}{c}\text { Guggenheim } \\
\begin{array}{c}\text { Anderson-Boer } \\
(\mathrm{GAB})\end{array}\end{array}$ & $M C=\frac{A B C a_{W}}{\left[\left(1-B a_{w}\right)+\left(1-B a_{w}+C K a_{w}\right)\right]}$ & $\mathrm{A}, \mathrm{B}, \mathrm{C}$ & [14] \\
\hline
\end{tabular}

The correlation coefficient (r) is one of the first criteria for predicting the best equation that describes the sorption isotherms. In addition to the correlation coefficient, the standard error of estimate (SEE) is used for the same purpose $[17,18]$. These statistical parameters are calculated as follows:

$$
\begin{aligned}
& r=\sqrt{\frac{\sum_{i=1}^{N}\left(\text { Xeq }_{i, p r e}-\overline{X e q}_{i, \exp }\right)^{2}}{\sum_{i=1}^{N}\left(\text { Xeq }_{i, \text { exp }}-\overline{X e q}_{i, \exp }\right)^{2}}} \\
& E S H=\sqrt{\frac{\sum_{i=1}^{N}\left(\text { Xeqi,exp }^{-X e q_{i}, p r e}\right)^{2}}{d_{f}}}
\end{aligned}
$$

Where $\mathrm{N}$ is the number of data points; Xeqi,exp is the experimental moisture content (\%d.b); Xeqi,pre is the predicted moisture content (\%d.b).

\subsection{The Specific surface area of adsorption}

Calculating the specific surface area of sorption is very useful in determining the strong bonds that exists between water and solid. In this regard, the calculation of the specific surface area of sorption is conducted via the following equation [9]:

$$
S S=\frac{M_{0} \times N_{A} \times A_{m}}{M_{\text {wat }}}=35.3 M_{0}
$$

Where SS designates the solid surface area of sorption (m2.g-1 solids); $\mathrm{M}_{0}$ refers to the monolayer moisture content (g/100 g, d.b); NA is the number of Avogadro (6.02 1023 molecules.mol ${ }^{-1}$ ); Am is the area of a water molecule (1.06 10-19 m²/molecule). Finally, the Mwat represents the molecular weight of the water $\left(18\right.$ g.mol $\left.{ }^{-1}\right)$.

\subsection{Net isosteric heat of adsorption}

In the hygroscopic domain where water is strongly bound to the product, the heat required to evaporate a water molecule is the sum of the latent heat of phase change and the heat of sorption. The heat of sorption can be determined from the desorption isotherms [19].

The application of the Clausius-Clapeyron equation to sorption isotherms (equilibrium isostatic pressure) at different temperatures is a widely used procedure for calculating the isosteric heat of sorption or the differential enthalpy of sorption, which is only valid for constant water contents.

$$
-\left(\frac{d \ln \left(P_{V}\right)}{d(1 / T)}\right)=\frac{\Delta H_{a}}{R}
$$

The net sorption enthalpy ( $\Delta$ ha), equation ( 7$)$ is defined by the subtraction of equation (5) predefined from the equation corresponding to pure water (6).

$$
\begin{aligned}
& -\left(\frac{d \ln \left(P_{v s a t}\right)}{d(1 / T)}\right)=\frac{\Delta H_{v a p}}{R} \\
& -\left(\frac{d \ln \left(\frac{P_{V}}{P_{V s a t}}\right)}{d(1 / T)}\right)_{E M C}=\frac{\Delta H_{a}-\Delta H_{V a p}}{R}=\frac{\Delta h_{a}}{R}
\end{aligned}
$$




\subsection{Differential entropy of adsorption}

The sorption differential entropy $(\Delta \mathrm{S})$ is another helpful thermodynamic property that seeks to analyze the degree of randomness or order of the state of the water molecules. What's more, the sorption entropy (differential entropy) is bound to the repulsive force attraction that exists in the food system [16]. The sorption entropy is demonstrated by the following equation:

$$
\ln \left(\mathrm{a}_{\mathrm{w}}\right)=\frac{-\Delta \mathrm{h}_{a}}{\mathrm{RT}}+\frac{\Delta \mathrm{S}}{\mathrm{R}}
$$

In which R stands for the universal gas constant $\left(8.314 \mathrm{~J} \cdot \mathrm{mol}^{-1} \cdot \mathrm{K}^{-1}\right)$.

\subsection{Theory of enthalpy-entropy compensation}

The theory of enthalpy-entropy compensation proposes a linear relationship between enthalpy and entropy given by the following relation (9):

$$
\Delta \mathrm{h}_{\mathrm{a}}=\mathrm{T}_{\beta} \Delta \mathrm{S}+\Delta \mathrm{G}_{\beta}
$$

$\mathrm{T} \beta$ is the isokinetic temperature at which all reactions in the series proceed at the same rate of progress. $\Delta \mathrm{G} \beta$ is the free energy at the temperature $T \beta[9,19]$. The sign of free energy $(\Delta G \beta)$ provides a criterion for evaluating whether the process of desorption is spontaneous $(-\Delta \mathrm{G} \beta)$ or not $(+\Delta \mathrm{G} \beta)$. The harmonic temperature $\left(\mathrm{T}_{\mathrm{hm}}\right)$ is given by the following relation (10):

$$
\mathrm{T}_{\mathrm{hm}}=\frac{n}{\sum_{1}^{n}\left(\frac{1}{\mathrm{~T}(\mathrm{~K})}\right)}
$$

Where $\mathrm{n}$ is the number of isotherms, $\mathrm{T}(\mathrm{K})$ in the oven temperatures in Kelvin.

\section{Results and discussion}

\subsection{Moisture adsorption of the powder of Taraxacum Officinale}

Table 2 summarizes the values of Guggenheim Anderson-Boer parameters. We can note from this table that GAB model is suitable to fit the experimental data of moisture adsorption of Taraxacum Officinale's powder at three temperatures $30,4050^{\circ} \mathrm{C}$, with a correlation coefficient $(\mathrm{r}=0.9984, \mathrm{r}=0.9985, \mathrm{r}=0.9988)$, and the standard error of estimate $(\mathrm{SEH}=1.8786, \mathrm{SEH}=1.6797, \mathrm{SEH}=1.4255)$ respectively. what's more the table displays that the equilibrium water content at the saturation level of the monolayer is between 7.6767 and 8.0019 (\%d.b).

TABLE 2. The values of Guggenheim Anderson-Boer parameters

\begin{tabular}{cccc}
\hline GAB & \multicolumn{3}{c}{ Adsorption } \\
\cline { 2 - 4 } parameters & $\mathbf{3 0}^{\circ} \mathbf{C}$ & $\mathbf{4 0}^{\circ} \mathbf{C}$ & $\mathbf{5 0}^{\circ} \mathbf{C}$ \\
\hline A & 8.0019 & 7.8700 & 7.6767 \\
B & 0.9880 & 0.9920 & 0.9985 \\
C & 7.8600 & 5.6600 & 2.7500 \\
r & 0.9984 & 0.9985 & 0.9988 \\
SEH & 1.8786 & 1.6797 & 1.4225 \\
\hline
\end{tabular}

The hygroscopic equilibrium is reached for the Taraxacum Officinale powder after 14 days for the adsorption process. Figure 3 presents the adsorption curves modeled by the GAB model, it shows that for a constant relative humidity, the water content at $30^{\circ} \mathrm{C}$ is higher than that at $40^{\circ} \mathrm{C}$. The curves also show that the sorption isotherms have a sigmoidal appearance, similar to those commonly presented by other aromatic and medicinal products $[10,14,19]$.

\subsection{The determination of the specific surface area of adsorption}

Using equation (4) the values of the specific surface area values of adsorption were calculated. The M0, which refers to the GAB monolayer moisture, is obtained from the GAB model. On one hand, the adsorption surface area of Taraxacum officinale' powder at $30^{\circ} \mathrm{C}, 40^{\circ} \mathrm{C}$ and $50^{\circ} \mathrm{C}$ temperatures take the values of $284,067 \mathrm{~m}^{2} \cdot \mathrm{g}^{-1}, 279,24$ 
$\mathrm{m}^{2} \cdot \mathrm{g}^{-1}, 272,52 \mathrm{~m}^{2} \cdot \mathrm{g}^{-1}$ respectively. We can conclude that the temperature affects the interaction between the water and solid surface area, it decreases with the increase of the temperature[10,20].
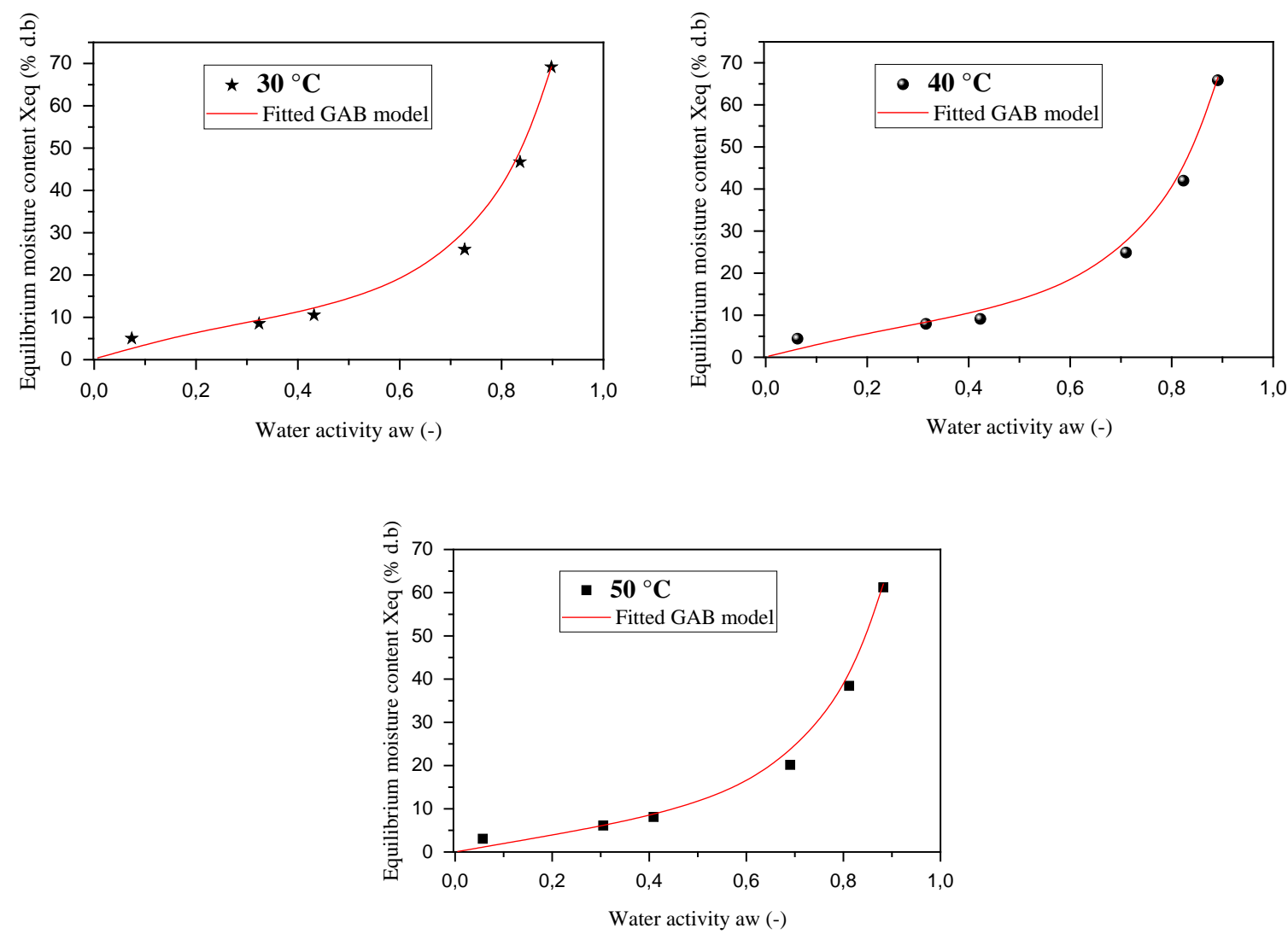

FIGURE 3. Comparison between experimental sorption data and that predicted by the GAB model

\subsection{The Calculation of the net isosteric heat of adsorption}

The values of $\Delta$ ha are obtained from the slope of the evolution of -ln (aw) as a function of (1/T) for a fixed equilibrium moisture content. A graphical representation of this equation is given in figure 4 . The net heat of adsorption equals the slope of each isostere (an isosteric curve corresponds to the set of points with the same EMC). This calculation method is currently the most used one in thermophysical studies. As it is shown in figure 4, the slope of the isostere of $\mathrm{EMC}=16$ is above that of $\mathrm{EMC}=14$, and it descends along with the decrease of the equilibrium water content [14].

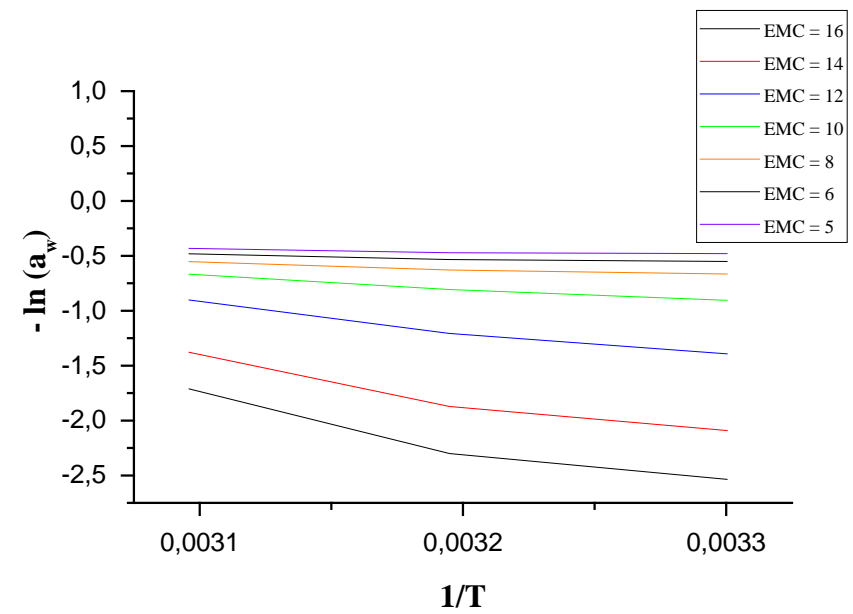

FIGURE 4. The Isosteric curves $\left(1 / \mathrm{T},-\ln \left(\mathrm{a}_{\mathrm{w}}\right)\right)$ at different EMC 
When water vapor is adsorbed on a surface, a quantity of heat (the heat of adsorption) is released. It corresponds to the energy that must be added to the adsorbed gas to break the intermolecular force. The adsorption heats indicate binding energy or intermolecular force between molecules of water vapor and the surface of the adsorbent (wet product) $[20,21]$.

The isosteric net of water adsorption on Taraxacum Officinale's powder decreases with increasing equilibrium moisture content (Figure 5). The enthalpy reaches a high value of enthalpy at low equilibrium moisture contents. This indicates a strong bond of water in the product being dried. The maximum enthalpy of adsorption reaches the value of $33.37156 \mathrm{~kJ} / \mathrm{mol}$. The equation (11) represents the relationship between the isosteric heat of adsorption data and the equilibrium moisture content. This model has been determined in order to predict the required heat of adsorption that must be added to fix a specific amount of water [20].

$$
\begin{aligned}
& \Delta h_{a}=59.28-4.64 E M C-0.17 E M C^{2}+0.015 E M C^{3} \\
& r=0.9964
\end{aligned}
$$

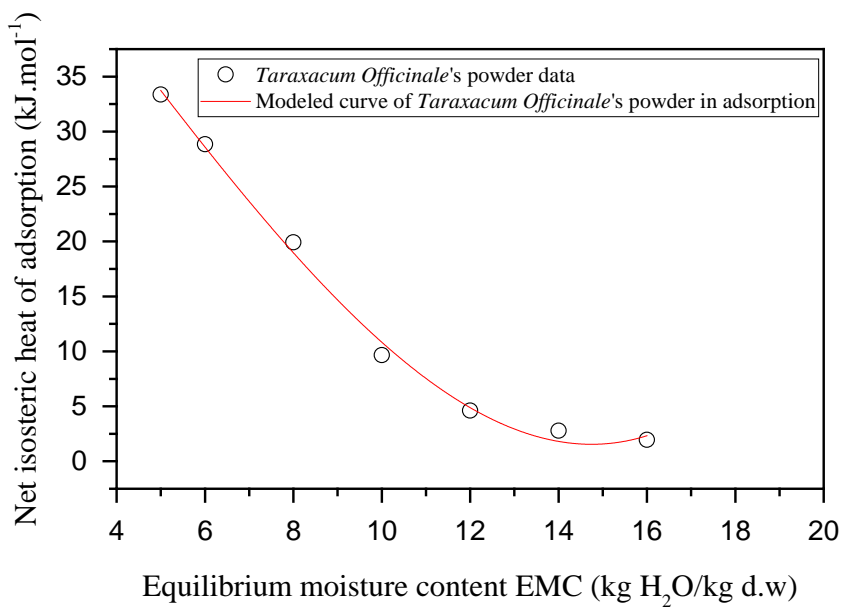

FIGURE 5. Variation of the net isosteric heat of moisture adsorption of Taraxacum Officinale's powder as a function of the EMC

\subsection{The calculation of the differential entropy of adsorption}

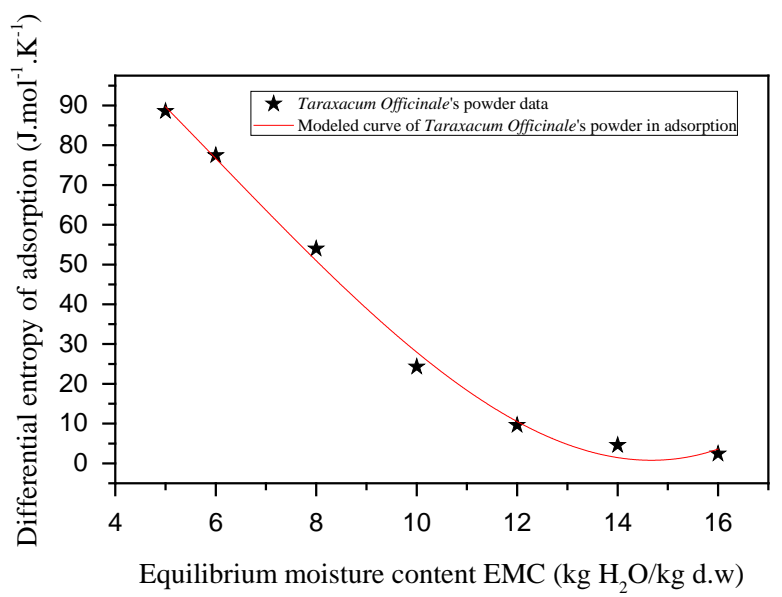

FIGURE 6. Variation of the differential entropy of adsorption of Taraxacum Officinale's powder as a function of the EMC

The evolution of the adsorption entropy as a function of the equilibrium moisture content of Taraxacum Officinale's powder is shown in Figure 6. The evolution of entropy is similar to that of the isosteric heat of adsorption. It is highly dependent on moisture content, especially for low equilibrium moisture content. The maximum adsorption entropy reaches values of $18.5793 \mathrm{~J} \cdot \mathrm{mol}^{-1} \cdot \mathrm{K}^{-1}$ at equilibrium moisture content EMC $=5$. The 
following equation represents the relationship between the differential entropy data and the equilibrium moisture content:

$$
\begin{aligned}
& \Delta S=59.28-4.064 E M C-0.17 E M C^{2}+0.015 E M C^{3} \\
& r=0.9996
\end{aligned}
$$

\subsection{Application of the enthalpy-entropy compensation theory}

Figure 7 presents the evolution of the net isosteric heat of adsorption as a function of the differential entropy. The thermodynamic properties released from the studied product are correlated by the following linear functions equation (13):

$$
\begin{aligned}
& \Delta \mathrm{h}_{\mathrm{a}}=360.68 \Delta \mathrm{S}+1009.91 \\
& r=0.9994
\end{aligned}
$$

The isokinetic temperature $(\mathrm{T} \beta)$ and free energy were determined by linear regression of equation (13).

Values of isokinetic temperature (T $\beta$ ) for Taraxacum Officinale's powder in the adsorption process is 360,68 $\mathrm{K}$. The harmonic temperature $\mathrm{T}_{\mathrm{hm}}$ is equal to $312,78 \mathrm{~K}\left(\approx 40^{\circ} \mathrm{C}\right)$ of the study. The isokinetic temperature of the studied powder is different from the harmonic one. This result confirms the existence of enthalpy-entropy compensation theory and the moisture sorption of Taraxacum Officinale's powder is an enthalpy driven process. The sign of the free energy $(\Delta \mathrm{G} \beta)$ of the powder is positive, which indicates that the water adsorption is a nonspontaneous process $[9,10,20]$.

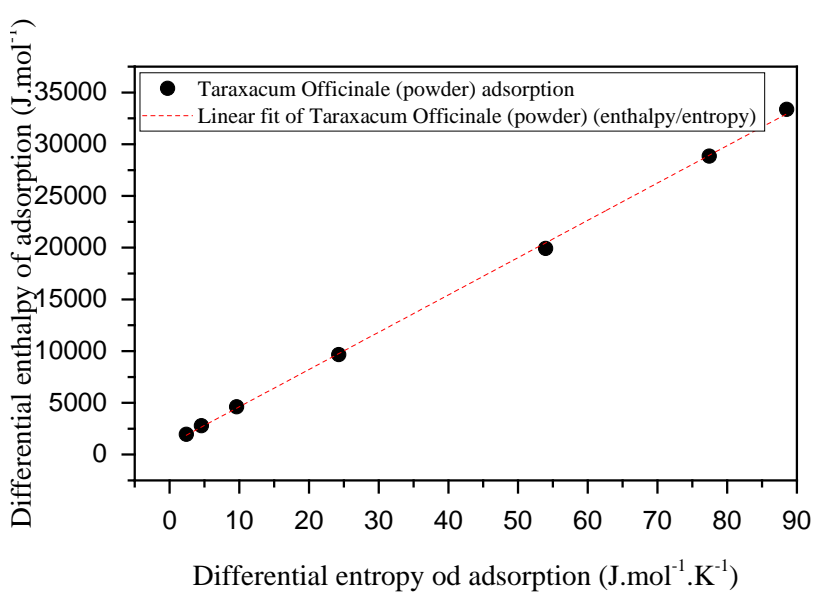

FIGURE 7. Variation of the differential enthalpy as a function of the differential entropy of Taraxacum Officinale's powder

\section{Conclusion}

This work has been devoted to the study of adsorption isotherms and the thermodynamic properties of the Taraxacum Officinale leave's powder. The desorption isotherms were determined using the gravimetric static method. The results of this study show that the adsorption isotherms of the product have a sigmoidal type II form. The water content equilibrium decreases with decreasing water activity at a constant temperature. The isosteric heat was determined by applying the Clausius-Clapeyron equation. The adsorption enthalpy is important at low moisture content as it decreases with increasing moisture content until it reaches the latent heat of evaporation from the water. Similar behaviors of the differential entropy as a function of the water content was found. For the Taraxacum Officinale leaves powder, the isokinetic temperature is different from the harmonic one, which confirms the existence of enthalpy-entropy compensation theory.

\section{Acknowledgments}

We are grateful to Mr. Brahim EL FADILI for his valuable help and financial support. We would like to thank Mr. Mohammed Benouara, a phytotherapist in Settat, Morocco, for his valuable assistance in obtaining the Taraxacum Officinale during this study. 


\section{References}

[1] Moussaoui H, Idlimam A, Lamharrar A. The Characterization and Modeling Kinetics for Drying of Taraxacum Officinale Leaves in a Thin Layer with a Convective Solar Dryer. Lect Notes Electr Eng. 2019:656-663. https://doi.org/10.1007/978-981-13-1405-6_75.

[2] Escudero NL, De Arellano ML, Fernández S, Albarracín G, Mucciarelli S. Taraxacum officinale as a food source. Plant Foods Hum Nutr. 2003;58:1-10. https://doi.org/10.1023/B:QUAL.0000040365.90180.b3.

[3] Moussaoui H, Lamsyehe H, Idlimam A, Lamharrar A, Kouhila M. Experimental study of the impact of drying parameters on dandelion root by a solar dryer. Adv. Intell. Syst. Comput. 2019. https://doi.org/10.1007/9783-030-12065-8_2.

[4] Moussaoui H, Aghzzaf AA, Idlimam A. Modeling of a Forced Convection Solar Drying System by Experimental Designs. In: (eds.) AK et al., editor. Recent Adv. Environ. Sci. from Euro-Mediterranean Surround. Reg., Advances in Science, Technology \& Innovation. Springer International Publishing; 2018. p. 1497-1499. https://doi.org/https://doi.org/10.1007/978-3-319-70548-4_436.

[5] Bahammou Y, Moussaoui H, Lamsayeh H, Tagnamas Z, Kouhila M, Ouaabou R, et al. Water sorption isotherms and drying characteristics of rupturewort (Herniaria hirsuta) during a convective solar drying for a better conservation. Sol Energy. 2020;201:916-26. https://doi.org/https://doi.org/10.1016/j.solener.2020. 03.071.

[6] Hamza L, Mounir K, Younes B, Zakaria T, Haytem M, Hind M, et al. Physicochemical study of the conservation of Moroccan anchovies by convective solar drying. Renew Energy. 2020;152:44-54. https://doi.org/10.1016/j.renene.2020.01.039.

[7] Al-Muhtaseb AH, McMinn WAM, Magee TRA. Water sorption isotherms of starch powders. Part 2: Thermodynamic characteristics. J Food Eng. 2004;62:135-42. https://doi.org/10.1016/S02608774(03)00202-4.

[8] Moussaoui H, Idlimam A, Lamharrar A, Tagnamas Z. Modeling of mass transfer during continuous drying of Urtica urens leaves. Arabian Journal of Medicinal and Aromatic Plants. 2020;6:36-53. https://doi.org/10.48347/IMIST.PRSM/ajmap-v6i1.20415

[9] Tagnamas Z, Moussaoui H, Bahammou Y, Kouhila M, Lamharrar A, Idlimam A. Enthalpy-Entropy Compensation in Carob Seeds Sorption Phenomena (Ceratonia selequa L.). In: A. Kallel et al. (eds.), editor. Recent Adv. Environ. Sci. from Euro-Mediterranean Surround. Reg., Advances in Science, Technology \& Innovation; 2018. https://doi.org/https://doi.org/10.1007/978-3-319-70548-4_398.

[10] Moussaoui H, Kouhila M, Lamsyehe H, Idlimam A, Lamharrar A. Moisture sorption measurements and Thecrmophysical characterization of the Taraxacum officinale leaves and root. Heat Mass Transf Und Stoffuebertragung. 2020. https://doi.org/10.1007/s00231-020-02838-5.

[11] Garcia-Perez JV., Carcel JA, Clemente G, Mulet A. Water sorption isotherms for lemon peel at different temperatures and isosteric heats. LWT - Food Sci Technol. 2008;41:18-25. https://doi.org/10.1016/j.lwt. 2007.02.010.

[12] Bahloul N, Boudhrioua N, Kechaou N. Moisture desorption-adsorption isotherms and isosteric heats of sorption of Tunisian olive leaves (Olea europaea L.). Ind Crops Prod. 2008;28:162-76. https://doi.org/10.1016/j.indcrop.2008.02.003.

[13] Moussaoui H, Lamsyehe H, Kouhila M, Bahammou Y, Tagnamas Z, Idlimam A, et al. Adsorption measurements and study of temperature and humidity influences on the dandelion leaves' powder. Moroccan J Chem. 2020;8:147-56. https://doi.org/https://doi.org/10.48317/IMIST.PRSM/morjchem-v8i1.15545.

[14] Moussaoui H, Bahammou Y, Idlimam A, Lamharrar A, Abdenouri N. Investigation of hygroscopic equilibrium and modeling sorption isotherms of the argan products: A comparative study of leaves, pulps, and fruits. Food Bioprod Process. 2019;114:12-22. https://doi.org/10.1016/j.fbp.2018.11.002.

[15] Jamali A, Kouhila M, Mohamed LA, Jaouhari JT, Idlimam A, Abdenouri N. Sorption isotherms of Chenopodium ambrosioides leaves at three temperatures. J Food Eng. 2006;72:77-84. https://doi.org/10.1016/j.jfoodeng.2004.11.021.

[16] Moussaoui H, Idlimam A, Lamharrar A, Kouhila M, Bahammou Y, Mouhib M, et al. The determination of moisture sorption isotherms and the isosteric heat of sorption for irradiated and non-irradiated durum wheat. Moroccan J Chem. 2020;4:866-78. https://doi.org/https://doi.org/10.48317/IMIST.PRSM/morjchem-v8i4. 19362.

[17] Touil A, Litaiem J, Zagrouba F. Sorption isotherms and thermodynamic properties of Allium sativum. J Tunis Chem Soc. 2015;17:105-14.

[18] Mghazli S, Idlimam A, Mahrouz M, Lahnine L, Hidar N, Ouhammou M, et al. Comparative moisture sorption isotherms, modelling and isosteric heat of sorption of controlled and irradiated Moroccan rosemary leaves. Ind Crops Prod. 2016;88:28-35. https://doi.org/10.1016/j.indcrop.2016.02.050.

[19] Machhour H, Idlimam A, Mahrouz M, El Hadrami I, Kouhila M. Sorption isotherms and thermodynamic 
properties of peppermint tea (Mentha piperita) after thermal and biochemical treatment. J Mater Environ Sci. 2012;3:232-47.

[20] Yogendrarajah P, Samapundo S, Devlieghere F, De Saeger S, De Meulenaer B. Moisture sorption isotherms and thermodynamic properties of whole black peppercorns (Piper nigrum L.). LWT - Food Sci Technol. 2015;64:177-88. https://doi.org/10.1016/j.lwt.2015.05.045.

[21] Moussaoui H, Aghzzaf AA, Idlimam A, Lamharrar A. Modeling of a Forced Convection Solar Drying System by Experimental Designs. In Euro-Mediterranean Conference for Environmental Integration. 2017;14971499. https://doi.org/10.1007/978-3-319-70548-4_436

(C) 2020 by the author(s). This work is licensed under a Creative Commons Attribution 4.0 International License (http://creativecommons.org/licenses/by/4.0/). Authors retain copyright of their work, with first publication rights granted to Tech Reviews Ltd. 